\title{
Management of EGFR mutated nonsmall cell lung carcinoma patients
}

\author{
Bogdan Grigoriu ${ }^{1}$, Thierry Berghmans ${ }^{2}$ and Anne-Pascale Meert ${ }^{2}$
}

Number 8 in the series "Challenges and controversies in thoracic oncology" Edited by J-P. Sculier, B. Besse and P. Van Schil

\author{
Affiliations: \\ ${ }^{1}$ Thoracic Oncology Dept, Regional Institute of Oncology lasi, University of Medicine and Pharmacy "Gr.T. \\ Popa", Iasi, Romania. \\ ${ }^{2}$ Service des soins intensifs et urgences oncologiques, et oncologie thoracique, Institut Jules Bordet, \\ Université Libre de Bruxelles (ULB), Brussels, Belgium.
}

\section{Correspondence:}

Anne-Pascale Meert, Institut Jules Bordet, 1 rue Héger-Bordet, 1000 Brussels, Belgium.

E-mail: ap.meertabordet.be

ABSTRACT Tyrosine kinase inhibitors (TKIs) targeting the epidermal growth factor receptor (EGFR) are common in the therapeutic armentarium of lung cancer today. Initially tested in an unselected population, they have been of limited usefulness until the identification EGFR gene mutations. Activating mutations generate conformational changes that result in a shift toward an active state of the catalytic domain and are associated with sensitivity to first generation EGFR TKI. Other mutations have been associated with resistance to these drugs, but for rare mutations there is limited data concerning their role in predicting response to EGFR TKI.

To date, four molecules have been approved for the treatment of EGFR mutated lung cancer. Gefitinib and/or erlotinib are available in almost all countries. Afatinib has been approved by the US Food and Drug Administration and by the European Medicines Agency, and icotinib has been approved only in China. Other, more active, third generation agents with a higher binding affinity for the receptor, or that are directed against specific mutations, are under development. EGFR TKIs have a favourable impact on progression-free survival when given as first line treatment in mutated patients, but may also have a moderate effect as a salvage therapy and in maintenance in an unselected population.

@ERSpublications

All patients with nonsquamous nonsmall cell lung cancer must be tested for the presence of EGFR activating mutations http://ow.ly/IdivY

\begin{abstract}
Previous articles in this series: No. 1: Powell HA, Baldwin DR. Multidisciplinary team management in thoracic oncology: more than just a concept? Eur Respir J 2014; 43: 1776-1786. No. 2: Shlomi D, Ben-Avi R, Balmor GR, et al. Screening for lung cancer: time for large-scale screening by chest computed tomography. Eur Respir J 2014; 44: 217-238. No. 3: De Ruysscher D, Nakagawa K, Asamura H. Surgical and nonsurgical approaches to small-size nonsmall cell lung cancer. Eur Respir J 2014; 44: 483-494. No. 4: Van Schil PE, Opitz I, Weder W, et al. Multimodal management of malignant pleural mesothelioma: where are we today? Eur Respir J 2014; 44: 754-764. No. 5: Kim L, Tsao MS. Tumour tissue sampling for lung cancer management in the era of personalised therapy: what is good enough for molecular testing? Eur Respir J 2014; 44: 1011-1022. No. 6: Blum T, Schönfeld N. The lung cancer patient, the pneumologist and palliative care: a developing alliance. Eur Respir J 2015; 45: 211-226. No. 7: Paesmans M, Grigoriu B, Ocak S, et al. Systematic qualitative review of randomised trials conducted in nonsmall cell lung cancer with a noninferiority or equivalence design. Eur Respir J 2015; 45: 511-524.
\end{abstract}

Received: Aug 272014 | Accepted after revision: Jan 122015 | First published online: Feb 192015

Conflict of interest: None declared.

Copyright OERS 2015 


\section{Introduction}

Over the past century, lung cancer has become one of the most frequent human tumours, due to the continuous spread of smoking despite solid evidence of its carcinogenic effect. Prognosis of advanced stage lung cancer is dismal, but initially improved over time, with clinical trials demonstrating median survivals of around 6 months after the introduction of cisplatin, then up to 9 months after large scale implementation of platinum doublet combinations in the 1980s [1]. Despite intense research and the introduction of a number of new chemotherapeutics, the prognosis for these advanced stages has not improve significantly since, and is similar with the most commonly used regimens today. Therefore, a change in the treatment paradigm became necessary; this was achieved either by giving "more chemotherapy", through the development of new and less toxic drugs in a "maintenance" strategy, or by a change from the "one size fits all" strategy of classical chemotherapy through the use of drugs that target specific abnormalities in each tumour. The better understanding of tumour biology led to the identification of specific biological pathways that were involved in their growth and which are differentially regulated from normal cells and from one tumour to another.

Signalling through the epidermal growth factor receptor (EGFR) pathway has been identified as being highly increased in a variety of tumours and particularly in lung cancers [2] and both monoclonal antibodies and small molecule inhibitors, initially selected on their potent inhibition of wild type EGFR, are now available. While monoclonal antibodies have proven to be effective in other cancers, for example colorectal or laryngeal cancers, in lung cancer this is still a matter of debate.

Early clinical trials of small molecule tyrosine kinase inhibitors (TKIs; mainly gefitinib and erlotinib) demonstrated that these drugs may be effective but, globally, the response rate (a still holy grail of measuring drug effectiveness today) was rather low in an unselected population. After an initial approval of gefitinib by the US Food and Drug Administration (FDA) in 2003 based on two small phase two trials [3, 4], prescription of the drug was afterwards restricted after a negative phase III trial [5]. For erlotinib, the BR21 phase III trial showed a modest benefit as a salvage therapy in an unselected population and the drug was finally approved by the FDA in 2004 [6].

However, when effective, tumour shrinking could be dramatic and this effectiveness was related to characteristics such as adenocarcinoma histology, TTF1 positivity, nonsmoker or light smoker status, female sex, and Asian descent.

At the same time, mechanistic research demonstrated that in adenocarcinomas sensitivity to these drugs is mainly related to the presence of specific mutations in the tyrosine kinase domain of the EGFR [7-9]. In contrast, multiple reports showed that expression of EGFR or copy number variations of the EGFR gene are not good predictive factors for the effectiveness of EGFR TKI [10].

\section{Function of EGFR tyrosine kinase domain and type of mutations encountered}

The EGFR receptor belongs to the HER receptor family which comprises four members (HER1 or EGFR, Her2/Neu, HER3 and HER4). Ligands and function are not identified for all members of this family but extensive data implicated them in cell growth, differentiation and migration [11]. The analysis of the structure of the EGFR receptor and its activation process [12] suggest that, upon ligand binding, there is a homo- or hetero-dimerisation of these receptors through a particular mechanism that involves a domain on each receptor. This results in an asymmetric apposition of the two receptor molecules in a "head to tail" configuration of the tyrosine kinase domains and subsequent shift to an active state of the tyrosine kinase domain and activation of downstream signalling. This shifting to an active state results from conformational changes of the tyrosine kinase domain. Specific mutations of the tyrosine kinase domain also result in conformational changes that shift the equilibrium towards an active state. These changes are specific for each mutation type and open the possibility of designing more specific inhibitors for each mutation (including those involving resistance to first generation TKIs) that can be more effective and have less inhibitory effect on wild-type EGFR, thus reducing drug side-effects (the majority of wild-type EGFR is located in the skin and digestive tract, which explains the main side-effects).

\section{Epidemiology of mutations}

A large number of mutations have been described for the EGFR gene and a public annotated database can be freely accessed on the internet (table 1) [39]. Almost all of these mutations are encountered in tumours with adenocarcinoma histology and are located in the tyrosine kinase domain. The most frequently encountered mutations are in-frame deletions in exon 19 (around 45\%) and a point mutation in exon 21 (L858R), which together account for over $85 \%$ of described mutations. The G719 A/C/S, L861Q mutations and exon 19 in-frame insertions account each for about $2 \%$ or less [35, 40, 41].

All of these mutations are associated with sensitivity to first generation TKIs. The response rate to these drugs is high (over 70\%) but there is no definitive explanation for non-responding patients carrying sensitising mutations. Other mutations have been associated with resistance to these drugs (for example T790M, which 
TABLE 1 Epidermal growth factor receptor mutations with their relative frequency and sensitivity to tyrosine kinase inhibitor (TKI)

Mutation Frequency Drug activity References

\begin{tabular}{lll}
\hline Exon 19 deletions $^{\#}$ & $45 \%$ & Sensitive to first generation TKI \\
L858R & $40 \%$ &
\end{tabular}

\begin{tabular}{|c|c|c|}
\hline In frame insertions exon 19 & $2 \%$ & Sensitive to first generation TKI \\
\hline G719X (A/C/S) & $2-3 \%$ & $\begin{array}{l}\text { Sensitive to first generation TKI } \\
\text { Possibly shorter response time }\end{array}$ \\
\hline L861 Q & $2 \%$ & Sensitive to first generation TKI \\
\hline L861 R & Rare & Resistance? \\
\hline Exon 20 in frame insertions & $\begin{array}{l}2 \% \text {; up to } 10 \% \text { in some } \\
\text { series }\end{array}$ & $\begin{array}{l}\text { Resistance to first generation TKI } \\
\text { Some - A763_Y764insFQEA - are sensitive to TKI }\end{array}$ \\
\hline T790M & $\begin{array}{l}\sim 50 \% \text { in progressing } \\
\text { patients under TKI } \\
\text { Rare in untreated } \\
\text { patients }\end{array}$ & $\begin{array}{l}\text { Resistance if secondary to treatment } \\
\text { Negative impact on response rate and survival: } \\
\text { may sometimes respond to first generation TKI }\end{array}$ \\
\hline
\end{tabular}

D761Y

L747 P/S

S768I

H870R

Other mutations: S720F, I715S, L862V, S784F

Rare

Uncertain significance, possible partial resistance

Uncertain significance, possible partial resistance

Resistance to first generation TKI?

Sensitive to afatinib?

May occur in association with other mutations

Resistance?
Occur in association with other activating
mutations
Resistance?
Occur with other mutations
Shorten response time

Unknown
Costa et al. [13], 2007

Rosell et al. [14], 2009

MAEMONDo et al. [15], 2010

Mitsudomi et al. [16], 2010

Mok et al. [17], 2009

ZHоu et al. [18], 2011

SEquist et al. [19], 2013

HE et al. [20], 2012

WatAnABe et al. [21], 2014

De PAs et al. [22], 2011

PAo and Chmielecki [23], 2010

De PAs et al. [22], 2011

PAo and Chmielecki [23], 2010

OXNARD et al. [24], 2013

ArCILA et al. [25], 2013

YASUDA et al. [26], 2012

YASUDA et al. [27], 2013

Sun et al. [28], 2013

Yu et al. [29], 2014

Ding et al. [30], 2014

BALAK et al. [31], 2006

VAN DER WEKKEn et al. [32], 2012

Costa et al. [33], 2007

Costa et al. [34], 2008

Shigematsu et al. [35], 2005

De PAS et al. [22], 2011

J.C. Yang and co-workers, personal communication

Shigematsu et al. [35], 2005

De PAs et al. [22], 2011

Shigematsu et al. [35], 2005

De PAS et al. [22], 2011

TSAO et al. [36], 2005

LUDOVINI et al. [37], 2008

Compound mutations

Frequency unknown; few data exist and are mainly based on case reports

":There are several variants of exon 19 in frame deletions, some of them not encompassing the LRE region. Response to therapy may be different according to mutation type [38].

is rarely found in untreated patients). For a number of mutations that account only for a small proportion of patients, their relationship with structural variation, activation of kinase activity and sensitivity to existing drugs is more elusive and frequently there are not enough clinical data to make an evidence-based clinical decision. Moreover, these "rare" mutations are frequently missed if mutation testing is performing using targeted methods. 
The frequency of EGFR mutations in adenocarcinomas varies with the ethnic background of the population studied. It seems to be around at least $30-50 \%$ of patients with East-Asian descent and up to $15 \%$ in Caucasians and African-Americans [42].

\section{Methods of determination and suitable samples for analysis}

There are two types of approaches in seeking EGFR mutations in practice. "Open" strategies rely on the direct sequencing of the gene by different technologies after a first step of PCR amplification (Sanger sequencing, pyrosequencing or high throughput new generation sequencing) and have the theoretical advantage of being able to detect any type of mutation (known or not). Targeted mutation detection relies on various PCR, fragment analysis and/or hybridisation techniques detecting, in particular, mutations associated with clinical response to available drugs. Direct sequencing needs samples with a high tumour content (at least $5-10 \%$ of mutated alleles in the sample; preferably higher than $20 \%$ ) and, therefore, need good quality samples (usually with at least $20 \%$ tumour cells). PCR-based methods may be more sensitive (down to $1 \%$ or even $0.1 \%$ of mutated alleles can be detected) but detect only a limited number of mutations for which the clinical implications are clear $[43,44]$ and also rarely may lead to false-positive results. Mass spectrometry techniques are sensitive but are of a more limited availability. The results using different testing methods have a good concordance $[45,46]$. There is no strong international recommendation about the technique to be used for mutation detection [47].

More recently, immunohistochemistry analyses with specific monoclonal antibodies directed against major mutations associated with TKI sensitivity (exon 19 deletions and L858R point mutations) have shown encouraging results but this approach is not the standard promoted today [48].

Mutation testing can be performed on any sample type: resection specimens, biopsies, needle biopsies and aspirations, pleural fluid cytology (cytoblocs are preferred). The most important elements for a good result are: high tumour content and conditions of specimen preservation. FFPE samples are suitable for testing but acidic or heavy metal fixations are prohibited and fixation time should be reduced to the minimum. Generally, a tumour content of at least $20 \%$ is required but samples with less tumour content can be tested at a price of a diminished sensitivity of an unknown magnitude. Usually, enrichment in tumour cell content is obtaining by "macro-dissection" i.e. selection of areas with high tumour cell density by manually cutting specific areas in the paraffin bock or scratching glass slides based of the image of the classical HE stained section. Laser capture micro-dissection can be useful in analysing samples with very little tumour cell content, but adds cost and time to the analysis and needs specialised equipment and personnel. The origin of the sample is less important (primary tumour, metastasis) as it has been demonstrated that little EGFR heterogeneity exists as long as no previous TKI treatment has been performed [49]. More recently, "liquid biopsies", i.e. mutation detection from circulating tumour DNA found in plasma, can be performed but the sensitivity is diminished and therefore only positive results should be taken into consideration [50].

\section{Efficacy of EGFR TKI in lung cancer}

Four molecules have been approved for the treatment of EGFR mutated lung cancer (fig. 1). Gefitinib, and/or erlotinib are available in almost all countries but conditions for reimbursement differ. Afatinib (initially developed as a solution to resistance to first generation TKI) has been approved in the US by the FDA and by the European Medicines Agency in 2013. Finally, icotinib has been approved only in China in 2011. Third generation agents (with a higher binding affinity for the receptor or directed against specific mutations) are under development.

\section{EGFR TKI in unselected population of advanced nonsmall cell lung cancer}

If the EGFR mutation status is unknown or if there is no mutation, the administration of a TKI alone in first line instead of chemotherapy is associated with a deleterious effect in terms of response rate, progression-free survival and survival (TORCH study) [51].

In non-progressing advanced nonsmall cell lung cancer (NSCLC) patients having received six cycles of first line chemotherapy plus the TKI (gefitinib or erlotinib) or placebo [52-55], maintenance by EGFR TKI gives no survival advantage. However, when given as maintenance after four cycles of a platinum-based chemotherapy in non-progressing patients who did not receive a TKI in the induction phase, progression-free survival was significantly longer with EGFR TKI [18] and a survival improvement was noted (SATURN) [56] but this improvement is small in non-mutated patients.

Intercalation of erlotinib during chemotherapy significantly prolonged progression-free survival of patients treated with first line platinum-based chemotherapy, but the effect is essentially seen in EGFR-mutated patients [57]. 


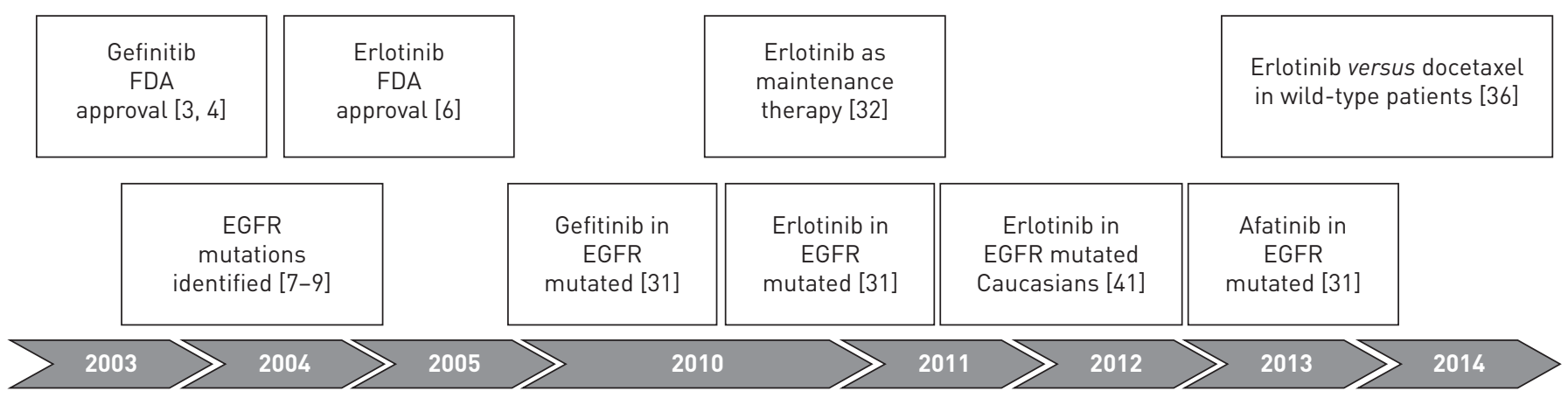

FIGURE 1 Epidermal growth factor receptor (EGFR) tyrosine kinase inhibitor key trials and drugs approval. FDA: US Food and Drug Administration.

In contrast, sequential administration of platinum doublet chemotherapy followed by gefitinib shows no overall benefit over continuous platinum doublet chemotherapy, while an improvement in survival is suggested in adenocarcinomas [58].

BR.21 is the first placebo controlled randomised study showing that an oral EGFR TKI prolongs survival (6.7 months versus 4.7 months) in stage IIIB or IV NSCLC, previously treated by one or two chemotherapy regimens [6]. While survival differences were not statistically significant between gefitinib and placebo in the ISEL trial [5], a trend favouring TKI administration was observed. Both trials were performed in an unselected population. In second line, the INTEREST study [59] established that gefitinib is not inferior to docetaxel, suggesting that gefitinib may be an option for pre-treated patients with advanced NSCLC. Nevertheless, it needs to be pointed out that, in tumours without EGFR mutation, docetaxel is superior to erlotinib in terms of progression-free survival, with survival results pending (TAILOR study) [60].

A meta-analysis has also shown that chemotherapy significantly improves progression free survival but not survival, compared with EGFR-TKIs as a second line treatment in advanced NSCLC with wild-type EGFR [61].

Taken together, these data shows that today there is little to support administration of EGFR inhibitors in unselected adenocarcinomas.

\section{EGFR TKI in enriched population}

It has been shown that TKI had a preferential activity in some subgroups: women, adenocarcinoma, nonsmokers and individuals of East-Asian ethnicity. When given front line in this enriched population, TKIs are effective in terms of response rate and progression free survival [17]. However, these characteristics also predict the presence of EGFR activating mutations that are sensitive to available TKI inhibitors and therefore such a clinical strategy for selecting patients is not recommended.

\section{EGFR TKI in EGFR-mutated patients}

Four published studies [15, 18, 62, 63] showed that first line, first generation EGFR TKI (gefitinib or erlotinib) for patients harbouring tumours with EGFR-activating mutations improved progression-free survival, with acceptable toxicity, as compared with standard platinum-based chemotherapy (table 2). Patients with EGFR activating mutations received a TKI, either in first or second line. No effect on survival was noted, probably because of the large crossover between TKI and chemotherapy arms at progression. The activity of EGFR TKI was demonstrated in both Asian and Caucasian populations, confirming that sensitivity to treatment was not an ethnic phenomenon but is due to the presence of the activating mutation. This efficacy was evaluated in a meta-analysis of six randomised trials [65] including enriched or mutation carrier populations. A greater response rate (relative risk 5.68, 95\% CI 3.17-10.18) and longer progression-free survival (hazard ratio (HR) 0.37 , 95\% CI $0.27-0.52$ ) were observed in favour of gefitinib or erlotinib, with no significant impact on survival (HR 0.94, 95\% CI 0.77-1.15).

Afatinib has also been associated with prolonged progression-free survival when compared with standard doublet chemotherapy in patients with advanced lung adenocarcinoma and EGFR mutations (LUX-Lung 3 trial) [19]. Median progression-free survival was 11.1 months for afatinib and 6.9 months for chemotherapy (HR 0.58, 95\% CI 0.43-0.78; p=0.001). Median progression-free survival among those with exon 19 deletions and L858R EGFR mutations was 13.6 months for afatinib and 6.9 months for chemotherapy (HR 0.47, 95\% CI 0.34-0.65; $\mathrm{p}=0.001$ ).

In the LUX-Lung 6 trial, 364 treatment-naive EGFR-mutated Asian patients (stage IIIB or IV cancer) were randomly assigned (2:1) to receive either oral afatinib (40 mg per day) or intravenous gemcitabine 
TABLE 2 Phase III randomised studies assessing the role of epidermal growth factor receptor (EGFR) tyrosine kinase inhibitor in first line in advanced and metastatic nonsmall cell lung cancer patients with EGFR mutation

\begin{tabular}{|c|c|c|c|c|c|c|}
\hline Reference & Treatment & Patients $\mathbf{n}$ & Objective response & p-value & Median survival & p-value \\
\hline INOUE et al. [62], 2013 & CBDCA+paclitaxel & 114 & $30.7 \%$ & & 26.6 months & \\
\hline Mitsudomi et al. [16], 2010 & CDDP+docetaxel & 86 & & & 30.9 months & \\
\hline \multirow[t]{2}{*}{ Rosell et al. [63], 2012} & Erlotinib & 86 & $58 \%$ & $\mathrm{~s}$ & 19.3 months & NS \\
\hline & Standard chemotherapy & 87 & $15 \%$ & & 19.5 months & \\
\hline Zнои et al. [18], 2011 & Erlotinib & 83 & $82 \%$ & $\mathrm{~s}$ & 22.7 months & 0.69 \\
\hline \multirow[t]{2}{*}{ SEQuist et al. [19], 2013} & Afatinib & 230 & $56 \%$ & 0.001 & HR 1.12 & 0.60 \\
\hline & CDDP-pemetrexed & 115 & $23 \%$ & & & \\
\hline \multirow[t]{2}{*}{ Wu et al. [64], 2014} & Afatinib & 242 & $66.9 \%$ & 0.0001 & 22.1 months & 0.76 \\
\hline & CDDP gemcitabine & 122 & $23 \%$ & & 22.2 months & \\
\hline
\end{tabular}

CBDCA: carboplatin; CDDP: cisplatin; S: significant: NR: not reached; NS: nonsignificant; HR: hazard ratio.

$1000 \mathrm{mg} \cdot \mathrm{m}^{-2}$ on day 1 and 8 plus cisplatin $75 \mathrm{mg} \cdot \mathrm{m}^{-2}$ on day 1 of a 3 -week schedule for up to six cycles [64]. Median progression-free survival was significantly longer in the afatinib group (11.0 months, 95\% CI 9.7-13.7 months) than in the gemcitabine and cisplatin group (5.6 months, 95\% CI 5.1-6.7; HR 0.28, 95\% CI $0.20-0.39 ; \mathrm{p}<0.0001)$. Moreover, in a combined secondary analysis of LUX-Lung 3 and 6 , afatinib seems to give an advantage in term of overall survival for patients with an exon 19 deletion but not in those with L858R mutation.

A study comparing gefitinib to afatinib as first line treatment for patients with metastatic EGFR-mutant lung cancer is currently ongoing (LUX-Lung 7, NCT01466660).

Another meta-analysis of eight randomised phase III trials comparing first line therapies with gefitinib, erlotinib or afatinib with chemotherapy showed a better progression-free survival in the EGFR TKI group, with no difference in terms of survival and no difference between the EGFR TKI [66].

The time of administration of TKI in these populations remains a matter of controversy. There are no data specifically assessing this question. However, as no difference in survival was observed in randomised trials, this suggests that it may be given as first line or as salvage therapy. Preference is generally given to first line treatment because not all patients may have access to these drugs in a second line of treatment, either because of serious deterioration of health status, significant toxicities or death due to disease progression. Patients who have received both treatments (EGFR TKI and chemotherapy) sequentially have the best survival.

\section{Resistance to EGFR TKI}

Despite their dramatic effect in patients harbouring sensitive EGFR mutations, administration of TKI results invariably in tumour regrowth. Mechanisms of resistance are multiple but involve acquired T790M resistance mutation in exon 20 in about $50 \%$ of patients and Met overexpression [67]. Other resistance mechanisms involve a mutation of K-RAS or use by the cancer cell signalling pathways redundant to that of epidermal growth factor. Intriguingly, but with a major therapeutic implication, some authors have described a transformation of NSCLC in small cell lung cancer $[68,69]$.

The diversity of mechanisms involved and the availability of specific interventions in some of these situations now warrant a systematic re-biopsy of the progressing tumour in patients previously receiving TKI for their management.

Early trials evaluating afatinib in patients progressing after a previous first generation TKI have been disappointing [70].

For the third generation TKI, the chemical formulation is significantly different from previous TKI, and some have a significant activity if the T790M mutation is present. Thus, the CO-1686 phase I trial shows a response rate of $64 \%$ among 22 patients with this abnormality while the majority of them have already received first or second generation TKI. Similarly the AZD9291 drug seems to be also active with a good toxicity profile [71].

On the basis of the present dogma in oncology, we tend to interrupt ongoing therapy at disease progression. For TKIs, the situation may be different since with few exceptions the original mutation 
driving tumour development is still found if the tumour is re-biopsied. Abrupt stopping of the TKI can results in a rapid disease flare resulting in severe deterioration, hospitalisation or death in up to one third of patients [72]. There are still few data concerning the best attitude to have in that situation but available reports suggest that continuing the TKI administration can result in a survival benefit [73, 74]. However, the attitude must be adapted to the type of progression: patients relapsing on a single metastatic site may benefit from an aggressive treatment of the metastases (especially if these are localised in areas of poor drug penetration, for example the brain), asymptomatic patients with slow progression may continue TKI until symptomatic [75] while rapid progressing patients may be switched to chemotherapy. However, in absence of solid evidence, no strong recommendation on the best attitude can be given today.

Administration of chemotherapy after disease progression on TKIs can result in a diminishing volume of the tumour population harbouring the TKI resistance phenotype and subsequent response to re-administration of TKI inhibitors [76]. However, it is still unclear which patients may benefit from such an approach and which markers should be used to select these patients.

To act on several signalling pathways and mechanisms of resistance, the combination of EGFR TKI with another targeted agent (bortezomib, everolimus, bevacizumab , tivantinib, sorafenib, R1507, sunitinib or entinostat) has been tested in salvage. These results have been included in a meta-analysis [77] that suggests an increase in survival. However, the individual results of these studies are not significant and involve molecules with very different mechanisms of action. It is legitimate to question of the adequacy of such an aggregation of results in a heterogeneous environment.

\section{Toxicity of EGFR TKI}

The toxicity profile of different EGFR TKIs is quite similar and focuses on skin dryness, acneiform rash, asthenia and diarrhoea; fatal but rare risk of pulmonary toxicity requires cautious administration of these drugs in patients with predisposing diseases (pulmonary fibrosis) and in Asian patients. Given the toxicity data and activity, it begs the question of the relative effectiveness of different TKIs. A randomised phase II study compared erlotinib and gefitinib in enriched or an activating mutation carriers population [78]. No differences were found in the primary end-points (response, progression-free survival and survival) with a less favourable toxicity profile for erlotinib (dermal toxicity of grade $2 / 3: 43.7 \%$ versus $10.4 \%$ and fatigue: $16.7 \%$ versus $0 \%$ ).

\section{Efficacy of chemotherapy in EGFR-mutated NSCLC patients}

The efficacy of platinum-based chemotherapy was compared between patients with advanced nonsquamous NSCLC who harbour EML4-ALK, those who harbour EGFR mutations and those with neither molecular abnormality. Among 200 patients with advanced nonsquamous NSCLC, 9.0\% were positive for EML4-ALK, 15.5\% harboured EGFR mutations, and $75.5 \%$ were wild-type for both abnormalities. Platinum-based combination chemotherapy showed similar efficacies in the EML4-ALK, EGFR mutation and wild-type cohorts in terms of response rate and progression-free survival, and overall survival [79]. EML4-ALK-positive patients had an overall survival similar to that of wild-type patients (median overall survival 15.7 versus 15.2 months; $\mathrm{p}=0.591$ ). The overall survival of EGFR mutation-positive patients (median 24.8 months) tended to be longer than that of the EML4-ALK-positive cohort, but this difference was not statistically significant. The overall survival of EGFR mutation-positive patients was significantly greater than that of wild-type patients $(\mathrm{p}=0.013)$.

\section{Prognostic role of EGFR mutations}

High-quality clinical and laboratory data support the notion that EGFR-activating mutations identify a subset of NSCLC (i.e., a nonsmokers' lung cancer) with an inherently different biology and a marked dependence on the EGFR pathway. EGFR mutations are well-defined molecular predictors of benefit from treatment with EGFR TKIs but their prognostic role has also been assessed. In the IPASS study, which compared gefitinib and carboplatin/paclitaxel in previously untreated never-smokers and light ex-smokers with advanced pulmonary adenocarcinoma, there was no significant difference in survival for gefitinib versus carboplatin/paclitaxel in the subgroups of patients with EGFR mutation-positive tumours (21.6 versus 21.9 months) and EGFR mutation-negative tumours (median overall survival 11.2 versus 12.7 months) [80], but survival was globally better in patients with EGFR mutation in comparison to patients without mutation, suggesting that EGFR mutation could also be of prognostic significance.

\section{Sensitivity to first generation TKI according to mutation type}

The most common occurring mutations (exon 19 deletion and L858R mutations) are highly responsive to TKI with a response rate of about $70 \%$. Exon 19 deletions are associated with a better response and longer survival, both in retrospective [41, 81-83] and prospective series [14], but this is not found in all series [84]. 
Another group of activating mutations (G719X, L861 Q) is associated with increased EGFR signalling but sensitivity to first generation TKI is diminished, with possible shorter durations of response (table 1).

\section{Conclusions}

In advanced NSCLC patients with EGFR activating mutation, EGFR TKIs have a favourable impact on progression free survival and these abnormalities should be tested in all patients with nonsquamous histology. The treatment may be given as first line, salvage or maintenance therapy. The time of administration of TKI in these populations remains a matter of controversy as there is no impact on survival, probably because of the treatment crossover at disease progression. It is advisable that at progression a case by case discussion should be undertaken and, if possible, a biopsy of the progressing site obtained for molecular analysis. The toxicity of these agents are different from those of chemotherapy but may be very severe.

\section{References}

1 Sculier JP, Moro-Sibilot D. First- and second-line therapy for advanced nonsmall cell lung cancer. Eur Respir J 2009; 33: 915-930.

2 Yarden Y, Sliwkowski MX. Untangling the ErbB signalling network. Nat Rev Mol Cell Biol 2001; 2: 127-137.

3 Fukuoka M, Yano S, Giaccone G, et al. Multi-institutional randomized phase II trial of gefitinib for previously treated patients with advanced non-small-cell lung cancer (The IDEAL 1 Trial). J Clin Oncol 2003; 21: 2237-2246.

4 Kris MG, Natale RB, Herbst RS, et al. Efficacy of gefitinib, an inhibitor of the epidermal growth factor receptor tyrosine kinase, in symptomatic patients with non-small cell lung cancer: a randomized trial. JAMA 2003; 290: 2149-2158

5 Thatcher N, Chang A, Parikh P, et al. Gefitinib plus best supportive care in previously treated patients with refractory advanced non-small-cell lung cancer: results from a randomised, placebo-controlled, multicentre study (Iressa Survival Evaluation in Lung Cancer). Lancet 2005; 366: 1527-1537.

6 Shepherd FA, Rodrigues PJ, Ciuleanu T, et al. Erlotinib in previously treated non-small-cell lung cancer. $N$ Engl Med 2005; 353: 123-132.

7 Lynch TJ, Bell DW, Sordella R, et al. Activating mutations in the epidermal growth factor receptor underlying responsiveness of non-small-cell lung cancer to gefitinib. N Engl J Med 2004; 350: 2129-2139.

8 Pao W, Miller V, Zakowski M, et al. EGF receptor gene mutations are common in lung cancers from "never smokers" and are associated with sensitivity of tumors to gefitinib and erlotinib. Proc Natl Acad Sci USA 2004; 101: 13306-13311.

9 Paez JG, Janne PA, Lee JC, et al. EGFR mutations in lung cancer: correlation with clinical response to gefitinib therapy. Science 2004; 304: 1497-1500.

10 Parra HS, Cavina R, Latteri F, et al. Analysis of epidermal growth factor receptor expression as a predictive factor for response to gefitinib ('Iressa', ZD1839) in non-small-cell lung cancer. Br J Cancer 2004; 91: 208-212.

11 Citri A, Yarden Y. EGF-ERBB signalling: towards the systems level. Nat Rev Mol Cell Biol 2006; 7: 505-516.

12 Ferguson KM. Structure-based view of epidermal growth factor receptor regulation. Annu Rev Biophys 2008; 37: 353-373.

13 Costa DB, Kobayashi S, Tenen DG, et al. Pooled analysis of the prospective trials of gefitinib monotherapy for EGFR-mutant non-small cell lung cancers. Lung Cancer 2007; 58: 95-103.

14 Rosell R, Moran T, Queralt C, et al. Screening for epidermal growth factor receptor mutations in lung cancer. N Engl J Med 2009; 361: 958-967.

15 Maemondo $\mathrm{M}$, Inoue $\mathrm{A}$, Kobayashi $\mathrm{K}$, et al. Gefitinib or chemotherapy for non-small-cell lung cancer with mutated EGFR. N Engl J Med 2010; 362: 2380-2388.

16 Mitsudomi T, Morita S, Yatabe Y, et al. Gefitinib versus cisplatin plus docetaxel in patients with non-small-cell lung cancer harbouring mutations of the epidermal growth factor receptor (WJTOG3405): an open label, randomised phase 3 trial. Lancet Oncol 2010; 11: 121-128.

17 Mok TS, Wu YL, Thongprasert S, et al. Gefitinib or carboplatin-paclitaxel in pulmonary adenocarcinoma. N Engl J Med 2009; 361: 947-957.

18 Zhou $\mathrm{C}, \mathrm{Wu}$ YL, Chen G, et al. Erlotinib versus chemotherapy as first-line treatment for patients with advanced EGFR mutation-positive non-small-cell lung cancer (OPTIMAL, CTONG-0802): a multicentre, open-label, randomised, phase 3 study. Lancet Oncol 2011; 12: 735-742.

19 Sequist LV, Yang JC, Yamamoto N, et al. Phase III study of afatinib or cisplatin plus pemetrexed in patients with metastatic lung adenocarcinoma with EGFR mutations. J Clin Oncol 2013; 31: 3327-3334.

20 He M, Capelletti M, Nafa K, et al. EGFR exon 19 insertions: a new family of sensitizing EGFR mutations in lung adenocarcinoma. Clin Cancer Res 2012; 18: 1790-1797.

21 Watanabe S, Minegishi Y, Yoshizawa H, et al. Effectiveness of gefitinib against non-small-cell lung cancer with the uncommon EGFR mutations G719X and L861Q. J Thorac Oncol 2014; 9: 189-194.

22 De Pas T, Toffalorio F, Manzotti M, et al. Activity of epidermal growth factor receptor-tyrosine kinase inhibitors in patients with non-small cell lung cancer harboring rare epidermal growth factor receptor mutations. $J$ Thorac Oncol 2011; 6: 1895-1901.

23 Pao W, Chmielecki J. Rational, biologically based treatment of EGFR-mutant non-small-cell lung cancer. Nat Rev Cancer 2010; 10: 760-774.

24 Oxnard GR, Lo PC, Nishino M, et al. Natural history and molecular characteristics of lung cancers harboring EGFR exon 20 insertions. $J$ Thorac Oncol 2013; 8: 179-184.

25 Arcila ME, Nafa K, Chaft JE, et al. EGFR exon 20 insertion mutations in lung adenocarcinomas: prevalence, molecular heterogeneity, and clinicopathologic characteristics. Mol Cancer Ther 2013; 12: 220-229.

26 Yasuda H, Kobayashi S, Costa DB. EGFR exon 20 insertion mutations in non-small-cell lung cancer: preclinical data and clinical implications. Lancet Oncol 2012; 13: e23-e31. 


\section{2: 6494-6501.} treatment. J Thorac Oncol 2012; 7: e8.

33 Costa DB, Halmos B, Kumar A, et al. BIM mediates EGFR tyrosine kinase inhibitor-induced apoptosis in lung cancers with oncogenic EGFR mutations. PLoS Med 2007; 4: 1669-1679.

34 Costa DB, Schumer ST, Tenen DG, et al. Differential responses to erlotinib in epidermal growth factor receptor (EGFR)-mutated lung cancers with acquired resistance to gefitinib carrying the L747S or T790M secondary mutations. J Clin Oncol 2008; 26: 1182-1184.

35 Shigematsu H, Lin L, Takahashi T, et al. Clinical and biological features associated with epidermal growth factor receptor gene mutations in lung cancers. J Natl Cancer Inst 2005; 97: 339-346.

36 Tsao MS, Sakurada A, Cutz JC, et al. Erlotinib in lung cancer - molecular and clinical predictors of outcome. N Engl J Med 2005; 353: 133-144.

37 Ludovini V, Gori S, Pistola L, et al. Long-lasting complete remission with tyrosine kinase inhibitor in bronchioloalveolar carcinoma with a so far unknown EGFR mutation. J Thorac Oncol 2008; 3: 452-453.

38 Chung KP, Wu SG, Wu JY, et al. Clinical outcomes in non-small cell lung cancers harboring different exon 19 deletions in EGFR. Clin Cancer Res 2012; 18: 3470-3477.

39 Catalogue Of Somatic Mutations In Cancer - COSMIC. http://cancer.sanger.ac.uk/cancergenome/projects/cosmic/ Date last accessed: June 5, 2014. Date last updated: September 17, 2014.

40 Sequist LV, Bell DW, Lynch TJ, et al. Molecular predictors of response to epidermal growth factor receptor antagonists in non-small-cell lung cancer. J Clin Oncol 2007; 25: 587-595.

41 Riely GJ, Politi KA, Miller VA, et al. Update on epidermal growth factor receptor mutations in non-small cell lung cancer. Clin Cancer Res 2006; 12: 7232-7241.

42 Serizawa M, Koh Y, Kenmotsu H, et al. Assessment of mutational profile of Japanese lung adenocarcinoma patients by multitarget assays: a prospective, single-institute study. Cancer 2014; 120: 1471-1481.

43 Newton CR, Graham A, Heptinstall LE, et al. Analysis of any point mutation in DNA. The amplification refractory mutation system (ARMS). Nucleic Acids Res 1989; 17: 2503-2516.

44 Whitcombe D, Theaker J, Guy SP, et al. Detection of PCR products using self-probing amplicons and fluorescence. Nat Biotechnol 1999; 17: 804-807.

45 Beau-Faller M, Blons H, Domerg C, et al. A multicenter blinded study evaluating EGFR and KRAS mutation testing methods in the clinical non-small cell lung cancer setting--IFCT/ERMETIC2 Project Part 1: Comparison of testing methods in 20 French molecular genetic National Cancer Institute platforms. J Mol Diagn 2014; 16: 45-55.

46 Young EC, Owens MM, Adebiyi I, et al. A comparison of methods for EGFR mutation testing in non-small cell lung cancer. Diagn Mol Pathol 2013; 22: 190-195.

47 Lindeman NI, Cagle PT, Beasley MB, et al. Molecular testing guideline for selection of lung cancer patients for EGFR and ALK tyrosine kinase inhibitors: guideline from the College of American Pathologists, International Association for the Study of Lung Cancer, and Association for Molecular Pathology. J Thorac Oncol 2013; 8: $823-859$.

48 Soma S, Tsuta K, Takano $\mathrm{T}$, et al. Intratumoral distribution of EGFR-amplified and EGFR-mutated cells in pulmonary adenocarcinoma. Pathol Res Pract 2014; 210: 155-160.

49 Kim HK, Lee HY, Choi YL, et al. Assessment of intratumoral heterogeneity of oncogenic driver mutations in surgically-resected lung adenocarcinoma: implications of percutaneous biopsy-based molecular assay for target-directed therapy. Anticancer Res 2014; 34: 707-714.

50 Bai H, Mao L, Wang HS, et al. Epidermal growth factor receptor mutations in plasma DNA samples predict tumor response in Chinese patients with stages IIIB to IV non-small-cell lung cancer. J Clin Oncol 2009; 27: 2653-2659.

51 Gridelli C, Ciardiello F, Gallo C, et al. First-line erlotinib followed by second-line cisplatin-gemcitabine chemotherapy in advanced non-small-cell lung cancer: the TORCH randomized trial. J Clin Oncol 2012; 30: 3002-3011.

52 Herbst RS, Giaccone G, Schiller JH, et al. Gefitinib in combination with paclitaxel and carboplatin in advanced non-small-cell lung cancer: a phase III trial-INTACT 2. J Clin Oncol 2004; 22: 785-794.

53 Herbst RS, Prager D, Hermann R, et al. TRIBUTE: a phase III trial of erlotinib hydrochloride (OSI-774) combined with carboplatin and paclitaxel chemotherapy in advanced non-small-cell lung cancer. J Clin Oncol 2005; 23: 5892-5899.

54 Giaccone G, Herbst RS, Manegold C, et al. Gefitinib in combination with gemcitabine and cisplatin in advanced non-small-cell lung cancer: a phase III trial-INTACT 1. J Clin Oncol 2004; 22: 777-784.

55 Gatzemeier U, Pluzanska A, Szczesna A, et al. Phase III study of erlotinib in combination with cisplatin and gemcitabine in advanced non-small-cell lung cancer: the Tarceva Lung Cancer Investigation Trial. J Clin Oncol 2007; 25: 1545-1552.

56 Cappuzzo F, Ciuleanu T, Stelmakh L, et al. Erlotinib as maintenance treatment in advanced non-small-cell lung cancer: a multicentre, randomised, placebo-controlled phase 3 study. Lancet Oncol 2010; 11: 521-529.

57 Mok T, Wu YL, Thongprasert S, et al. A randomized placebo-controlled phase III study of intercalated erlotinib with gemcitabine-platinum in first-line advanced non-small cell lung canccer (NSCLC): FASTACT-II. J Clin Oncol 2012; 30, Suppl.: 7519 . 
58 Takeda K, Hida T, Sato T, et al. Randomized phase III trial of platinum-doublet chemotherapy followed by gefitinib compared with continued platinum-doublet chemotherapy in Japanese patients with advanced non-small-cell lung cancer: results of a west Japan thoracic oncology group trial (WJTOG0203). J Clin Oncol 2010; 28: 753-760.

59 Kim ES, Hirsh V, Mok T, et al. Gefitinib versus docetaxel in previously treated non-small-cell lung cancer (INTEREST): a randomised phase III trial. Lancet 2008; 372: 1809-1818.

60 Garassino MC, Martelli O, Broggini M, et al. Erlotinib versus docetaxel as second-line treatment of patients with advanced non-small-cell lung cancer and wild-type EGFR tumours (TAILOR): a randomised controlled trial. Lancet Oncol 2013; 14: 981-988.

61 Zhao N, Zhang XC, Yan HH, et al. Efficacy of epidermal growth factor receptor inhibitors versus chemotherapy as second-line treatment in advanced non-small-cell lung cancer with wild-type EGFR: a meta-analysis of randomized controlled clinical trials. Lung Cancer 2014; 85: 66-73.

62 Inoue $\mathrm{A}$, Kobayashi $\mathrm{K}$, Maemondo $\mathrm{M}$, et al. Updated overall survival results from a randomized phase III trial comparing gefitinib with carboplatin-paclitaxel for chemo-naive non-small cell lung cancer with sensitive EGFR gene mutations (NEJ002). Ann Oncol 2013; 24: 54-59.

63 Rosell R, Carcereny E, Gervais R, et al. Erlotinib versus standard chemotherapy as first-line treatment for European patients with advanced EGFR mutation-positive non-small-cell lung cancer (EURTAC): a multicentre, open-label, randomised phase 3 trial. Lancet Oncol 2012; 13: 239-246.

$64 \mathrm{Wu}$ YL, Zhou C, Hu CP, et al. Afatinib versus cisplatin plus gemcitabine for first-line treatment of Asian patients with advanced non-small-cell lung cancer harbouring EGFR mutations (LUX-Lung 6): an open-label, randomised phase 3 trial. Lancet Oncol 2014; 15: 213-222.

65 Gao G, Ren S, Li A, et al. Epidermal growth factor receptor-tyrosine kinase inhibitor therapy is effective as first-line treatment of advanced non-small-cell lung cancer with mutated EGFR: a meta-analysis from six phase III randomized controlled trials. Int J Cancer 2012; 131: E822-E829.

66 Haaland B, Tan PS, de Castro G Jr, et al. Meta-analysis of first-line therapies in advanced non-small-cell lung cancer harboring EGFR-activating mutations. J Thorac Oncol 2014; 9: 805-811.

$67 \mathrm{Yu}$ HA, Arcila ME, Rekhtman N, et al. Analysis of tumor specimens at the time of acquired resistance to EGFR-TKI therapy in 155 patients with EGFR-mutant lung cancers. Clin Cancer Res 2013; 19: 2240-2247.

68 Sequist LV, Waltman BA, Dias-Santagata D, et al. Genotypic and histological evolution of lung cancers acquiring resistance to EGFR inhibitors. Sci Transl Med 2011; 3: 75ra26.

69 Watanabe S, Sone T, Matsui T, et al. Transformation to small-cell lung cancer following treatment with EGFR tyrosine kinase inhibitors in a patient with lung adenocarcinoma. Lung Cancer 2013; 82: 370-372

70 Miller VA, Hirsh V, Cadranel J, et al. Afatinib versus placebo for patients with advanced, metastatic non-small-cell lung cancer after failure of erlotinib, gefitinib, or both, and one or two lines of chemotherapy (LUX-Lung 1): a phase 2b/3 randomised trial. Lancet Oncol 2012; 13: 528-538.

71 Janne PA, Ramalingam SS, Yang J, et al. Clinical activity of the mutant-selective EGFR inhibitor AZD9291 in patients (pts) with EGFR inhibitor-resistant non-small cell lung cancer (NSCLC). J Clin Oncol 2014; 32, Suppl. 5: 8009.

72 Chaft JE, Oxnard GR, Sima CS, et al. Disease flare after tyrosine kinase inhibitor discontinuation in patients with EGFR-mutant lung cancer and acquired resistance to erlotinib or gefitinib: implications for clinical trial design. Clin Cancer Res 2011; 17: 6298-6303.

73 Nishie K, Kawaguchi T, Tamiya A, et al. Epidermal growth factor receptor tyrosine kinase inhibitors beyond progressive disease: a retrospective analysis for Japanese patients with activating EGFR mutations. J Thorac Oncol 2012; 7: 1722-1727.

74 Maruyama $\mathrm{R}$, Wataya $\mathrm{H}$, Seto $\mathrm{T}$, et al. Treatment after the failure of gefitinib in patients with advanced or recurrent non-small cell lung cancer. Anticancer Res 2009; 29: 4217-4221.

75 Oxnard GR, Lo P, Jackman DM. Delay of chemotherapy through use of post-progression erlotinib in patients with EGFR-mutant lung cancer. J Clin Oncol 2012; 30: A7547.

76 Kurata T, Tamura K, Kaneda H, et al. Effect of re-treatment with gefitinib ('Iressa', ZD1839) after acquisition of resistance. Ann Oncol 2004; 15: 173-174.

77 Qi WX, Wang Q, Jiang YL, et al. Overall survival benefits for combining targeted therapy as second-line treatment for advanced non-small-cell-lung cancer: a meta-analysis of published data. PLoS One 2013; 8: e55637.

78 Kim ST, Uhm JE, Lee J, et al. Randomized phase II study of gefitinib versus erlotinib in patients with advanced non-small cell lung cancer who failed previous chemotherapy. Lung Cancer 2012; 75: 82-88.

79 Takeda M, Okamoto I, Sakai K, et al. Clinical outcome for EML4-ALK-positive patients with advanced non-small-cell lung cancer treated with first-line platinum-based chemotherapy. Ann Oncol 2012; 23: 2931-2936.

80 Fukuoka M, Wu YL, Thongprasert S, et al. Biomarker analyses and final overall survival results from a phase III, randomized, open-label, first-line study of gefitinib versus carboplatin/paclitaxel in clinically selected patients with advanced non-small-cell lung cancer in Asia (IPASS). J Clin Oncol 2011; 29: 2866-2874.

81 Jackman DM, Yeap BY, Sequist LV, et al. Exon 19 deletion mutations of epidermal growth factor receptor are associated with prolonged survival in non-small cell lung cancer patients treated with gefitinib or erlotinib. Clin Cancer Res 2006; 12: 3908-3914.

82 Sun JM, Won YW, Kim ST, et al. The different efficacy of gefitinib or erlotinib according to epidermal growth factor receptor exon 19 and exon 21 mutations in Korean non-small cell lung cancer patients. J Cancer Res Clin Oncol 2011; 137: 687-694.

83 Won YW, Han JY, Lee GK, et al. Comparison of clinical outcome of patients with non-small-cell lung cancer harbouring epidermal growth factor receptor exon 19 or exon 21 mutations. J Clin Pathol 2011; 64: 947-952.

84 Sequist LV, Martins RG, Spigel D, et al. First-line gefitinib in patients with advanced non-small-cell lung cancer harboring somatic EGFR mutations. J Clin Oncol 2008; 26: 2442-2449. 